\title{
Sexual activity of pregnant Polish women and the assessment of the marital relation quality
}

\section{BACKGROUND}

The aim of the research was to present sexual functioning of pregnant women in terms of their assessment of the sexual life and marital relation. The study included 61 pregnant women ( 31 with high-risk pregnancy and 30 with a normal course of pregnancy), aged on average 28.5 years and pregnant on average for 27.5 weeks.

\section{PARTICIPANTS AND PROCEDURE}

The study was based on the sociodemographic questionnaire The Female Sexual Function Questionnaire, SFQ28 (designed by Quirk et al., 2005), the Sexual Quality of Life Questionnaire - Female Version, SQoL-F (designed by Symonds et al., 2005), and the Dyadic Adjustment Scale, DAS (designed by Cieślak, 1989).

\section{RESULTS}

The obtained results reveal changes in sexual functioning during pregnancy, mostly in terms of desire and excitement. The groups differed significantly in terms of sexual activity. Women with pathological pregnancy obtained lower results on the scales of desire, arousal, orgasm and satisfaction with sexual relationship. With every subsequent pregnancy week, both groups obtained lower results on the scales of arousal, orgasm and satisfaction with sexual activity. Neither pregnancy nor its length was related to the assessment of satisfaction with marital relation.

\section{CONCLUSIONS}

The conducted data analysis indicates that the subjective assessment of sexual life is related to the assessment of marital relation on the scale of emotional expression and relation coherence. No relation of sexual activity and sexual life with the assessment of the quality of marital relation was proved. However, the assessment of sexual life is related significantly to the assessment of the quality of marital relation.

\section{KEY WORDS}

sexual activity; pregnancy; marital relation quality; sexual life quality 


\section{BACKGROUND}

Pregnancy is a special time, which comprises a dynamic process of changes in the mind and organism of every woman. Partnership relations, behavioural patterns, mood and sexuality of women are changed (Makara-Studzińska, Wdowiak, Plewik \& Kryś, 2011; Trutnovsky, Haas, Lang \& Petru, 2006). Sexual life of pregnant women is still a taboo subject for many doctors and specialists, but also for pregnant women
Karolina Lutkiewicz, Mariola Bidzan themselves (Kitzinger, 1983; Makara-Studzińska et al., 2011; Murtagh, 2010; Rosen \& Barski, 2006). On the one hand sexual activity may be a risk factor, because an orgasm of a future mother may cause harm to a fetus. On the other hand, a sexual relationship between partners is considered to be a source of valuable psychological benefits, which improve the quality of life (Sydow, 1999). Scientists indicate that sexual life of women is conditioned by:

- the health condition of a pregnant woman,

- the emotional bond between spouses,

- sexual needs,

- the sexual life before pregnancy,

- the sense of their own self-esteem and attractiveness,

- the fear of a child experienced by both partners,

- embarrassment caused by the closeness of a fetus,

- social cultural traditions (Makara-Studzińska et al., 2011).

Many scientists have been interested in the issue of the need for closeness during pregnancy. The studies revealed that pregnant women have an increased need of hugging and touching. Women understand closeness as proximity without having sexual intercourse. In addition, the quality of partnership relation and the bond between spouses are crucial for sexual behaviours. Gynaecologists studying husband-wife relations during the first pregnancy revealed that couples found it very hard to adjust to their new roles. The study results indicate that sexual life of spouses during pregnancy may be regulated by female sexual desire (Lew-Starowicz, 1991; Lew-Starowicz \& Lew-Starowicz, 2001), which is in turn related to e.g. the perception of a woman's changing body. Changes in her body, larger breasts, stomach, enhanced vaginal discharge - it all affects a woman's self-assessment and self-esteem (Smoliński, 2010). Dissatisfaction with her own body and low sense of attractiveness may be the reason for avoiding sexual intercourse and intimate relations with her partner (Smoliński, 2010). The fact is that sexual relations are the most sensitive aspect of the relationship between young parents expecting their child (Sydow, 1999).

Many women believe that sexual activity diminishes in the course of pregnancy due to practical inconveniences (Kitzinger, 1983; Murtagh, 2010; Rosen $\&$ Barski, 2006). Tiredness is the factor which deter- mines the frequency of sexual intercourse (Kitzinger, 1983; Murtagh, 2010). On the other hand, it is well known that pregnant women feel sexual needs, which change during three different pregnancy phases. Due to this, sexual activity of pregnant women will be considered in terms of three trimesters of pregnancy (Smoliński, 2010). The first trimester of pregnancy is featured by decreased sexual needs and frequency of sexual intercourse. This state of affairs is affected by such symptoms experienced by women as drowsiness, breast tenderness, nausea, mood swings and fear of harming the embryo and causing miscarriage (Kitzinger, 1983; Lepiarz, 2010; Murtagh, 2010). At that time genitals undergo significant changes, which enhance erotic sensations, e.g. increased vascularization of the pelvis occurs (Makara-Studzińska et al., 2011). The first trimester and the beginning of the second trimester are characterized by increased sexual tension. During that time the vagina becomes more lubricated and it happens much quicker (Kitzinger, 1983; Makara-Studzińska et al., 2011). Studies conducted by Masters and Johnson indicate that - on the basis of conducted interviews - the second trimester of pregnancy is characterized by enhanced sexual activity and the quality of marital sexual intercourse (Lew-Starowicz, 1991; Lew-Starowicz \& Lew-Starowicz, 2001). Intense fantasies and erotic dreams and higher sexual satisfaction are related to strong congestion of genitals, quicker lubrication of vaginal walls and numerous hormonal changes (Kitzinger, 1983). The risk of miscarriage caused by sexual activity in the second trimester of pregnancy may occur with women who have lost their child many times due to miscarriage (Smoliński, 2010). Uterine contractions during intercourse may cause another miscarriage (Smoliński, 2010). Contractile activity of the uterus and uterine bleeding are factors which absolutely require the cessation of intercourse (Smoliński, 2010). In the third trimester of pregnancy women lose interest in sexual activity. The reason for this is greater fear for the child and many unpleasant somatic sensations. In the last trimester it is necessary to refrain from sexual intercourse due to the risk of causing a preterm birth. Uterine muscle may react with regular contractions to sexual arousal. Some pregnancy complications, e.g. bleeding, the risk of preterm birth or premature rupture of membranes, require the cessation of intercourse immediately (Makara-Studzińska et al., 2011).

Pregnant women discuss their sexual activity during pregnancy with physicians very rarely. Therefore many women seek information in guidebooks, books or media (Murtagh, 2010). Bartellas (2000) found out that $71 \%$ of pregnant women are less sexually active, compared to the time before pregnancy (Bartellas et al., 2000). The third trimester turned out to be the period when sexual behaviours are very rare. $96 \%$ of women had sexual intercourse with their 
partners during the first trimester, but only $67 \%$ of them continued their sexual activity to the third trimester (Bartellas et al., 2000; Murtagh, 2010). The fear of harming the fetus, of bleeding and of preterm delivery were significant factors preventing women from being sexually active (Bartellas et al., 2000; Lepiarz, 2010; Murtagh, 2010). Bartellas et al. (2000) discovered that sexual activity decreased systematically with every trimester, which was conditioned by the fear of harming the fetus and going into preterm labour (Bartellas et al., 2000; Murtagh, 2010). It started with $9 \%$ of women in the first trimester and rose to $21 \%$ of women in the second trimester and $49 \%$ of women in the third trimester. Sexual activity decreased proportionally to the increasing fear of causing preterm delivery (Bartellas et al., 2000).

Satisfaction with sexual life and sexual relationship with a partner is a significant factor determining the quality of a marital relation. Many authors think that sexual intercourse between spouses is the core constituent of a relationship, which allows them to develop love and a marital bond, and they find the quality of sexual initiation to be the most important factor conditioning further happiness in marital sexual life (Rostowski, 1987; Ryś, 1999).

Sexuality in a marital relation is affected not only by psychological factors, but also by one's own hierarchy of values, needs and many social conditions (Rostowski, 1987). It is also worth underlining that a satisfactory sexual life strengthens the emotional bond between partners, which in turn consolidates all other common actions (Rostowski, 1987; Ryś, 1999).

Another significant factor is an individual perspective, which includes personal variables, such as previous sexual experience of a person, which may e.g. prevent an individual from becoming fully sexually involved in a relationship. In addition, religious beliefs of spouses also inhibit sexual activity between them, leading to emotional and spiritual isolation. An important element of sexual life is the emotional bond between spouses. Sexual involvement is strictly related to emotional involvement of spouses. It is determined by a simple rule: the greater the emotional involvement, the larger the sexual involvement in a relation (Rostowski, 1987; Ryś, 1999; Sternberg \& Hojjat, 1997). Satisfactory sexual life in a marriage is conditioned by many factors - not only the quality of sexual intercourse, frequency or the sole fact of having an orgasm, but also knowledge about psychosexual differences between a man and a woman. In addition, the ability to communicate one's own needs, and establish a dialogue about one's expectations, develops a conscious relationship between partners, combined with the desire to be with each other. All this leads not only to sexual satisfaction of spouses, but also to a general sense of happiness in a relationship (Ryś, 1999).

The aim of the following thesis is to determine the relationship between sexual activity of pregnant women and the assessment of the quality of their marital relation.

\section{PARTICIPANTS AND PROCEDURE}

The study included 61 pregnant women. The examined group included 31 pregnant women, who were examined in the Clinic of Obstetrics at the Medical University of Gdańsk, at the Pregnancy Pathology Ward. The control group included 30 pregnant women with a normal course of pregnancy, examined in schools of birth in Gdańsk and Sopot. The study was anonymous.

The most frequently reported problem was complications related to twin pregnancies, which are classified as high-risk pregnancies. Five examined women suffered from diabetes, and 5 other women were threatened by preterm delivery. Patients also reported cholestasis, and 2 women had cysts on their ovaries. Other patients reported such difficulties as haematometra, cervical insufficiency, high-risk pregnancy (triplets), hypertension, genitourinary tract infections, and fetal tumour.

As illustrated in Table 1, 59\% of respondents $(N=36)$ were women aged between 25 and 30 years; $21 \%$ of respondents $(N=13)$ were aged between 31 and 36 years, and $13 \%(N=8)$ of respondents were women aged between 19 and 24 years. The average age of all respondents was 28.5 , standard deviation $S D=4$. The average length of pregnancy was 27.5 weeks, standard deviation $S D=10$. The average duration of the relationship of respondents was 4 years, standard deviation $S D=$ $=3.6$, with $57.4 \%(N=36)$ of women being in a relationship lasting shorter than 4 years, and $26.2 \%(N=16)$ being in a relationship lasting from 5 to 9 years.

During the study $63.93 \%(N=39)$ of women were in the third trimester of pregnancy, and $21.3 \%(N=13)$ of women were in the second trimester of pregnancy. The remaining $14.8 \%(N=9)$ of respondents were in the first trimester of pregnancy. Due to the uneven and too small number of respondents in each trimester, an analysis of sexual functioning in relation to different trimesters was not possible.

Table 1

Women age groups. Source: own work

\begin{tabular}{ccc}
\hline $\begin{array}{c}\text { Age groups } \\
\text { in years }\end{array}$ & $\begin{array}{c}\text { Number } \\
\text { of women }\end{array}$ & $\%$ \\
\hline $19-24$ & 8 & 13.1 \\
$25-30$ & 36 & 59.0 \\
$31-36$ & 13 & 21.3 \\
$37-42$ & 4 & 6.6 \\
Total & 61 & 100.0 \\
\hline
\end{tabular}

Sexual activity of pregnant women 
The research methods included:

1. The Female Sexual Function Questionnaire, SFQ28 (designed by Quirk et al., 2002);

2. Sexual Quality of Life Questionnaire - Female Version, SQoL-F (designed by Symonds, Boolell \& Quirk, 2005);

3. Dyadic Adjustment Scale, DAS (Polish version by Cieślak, 1989);

4. Sociodemographic questionnaire (own work).

The study was accepted by the Ethics Committee

Karolina Lutkiewicz, Mariola Bidzan at the Institute of Psychology, University of Gdańsk.

The SFQ28 questionnaire is a multidimensional tool that measures the sexual functioning of women. The questionnaire consists of 28 items. The SFQ28 questionnaire includes all phases of the sexual response cycle in women (desire, arousal, orgasm), and the presence of pain during sexual activity (dyspareunia) included in the diagnostic criteria of DSM-IV (Quirk et al., 2002). This questionnaire includes the following eight domains: desire, arousal (sensations), arousal expressed by lubrication, arousal as the cognitive component, orgasm, pain, satisfaction with sex and relationship with the partner (Quirk et al., 2002). The results of this questionnaire allowed us to specify the level of severity of sexual dysfunction and classify the female respondents into 3 categories: a high probability of the occurrence of sexual dysfunction, borderline sexual dysfunction level, and a high probability of normal sexual functioning (Quirk et al., 2002; Quirk, Haughie \& Symonds, 2005). The SFQ28 questionnaire has very good psychometric properties (Lew-Starowicz \& Rola, 2012). The SQoL-F questionnaire includes statements regarding the thoughts and feelings that may occur in women in relation to their sexual life (Symonds et al., 2005; Quirk et al., 2005). These statements may relate to the positive or negative aspects of sexual life. This questionnaire investigates the impact of female sexual dysfunction on the quality of their sexual life, considered in three areas: self-esteem, emotional well-being, and the relationship with the partner (Lew-Starowicz \& Rola, 2012). As factor analysis showed a strong correlation among the aforementioned categories, the results are calculated as the overall total score, rather than as separate domains (Symonds et al., 2005; Quirk et al., 2005). The Spanier DAS scale was used to assess the quality of the respondents' marriage. The Spanier questionnaire allows for a comprehensive assessment of the quality of the marital relation. The questionnaire consists of 32 statements, which were divided into four sub-scales. The following aspects of marital adjustment were taken into account:

a) consensus, understood as the degree of mutual understanding on issues significant for the functioning of a relationship,

b) cohesion, understood as the degree to which respondent and partner participate in everyday activities together, c) satisfaction with the relationship, understood as the general sense of satisfaction with the relationship and hence the will to remain in the relationship,

d) affectional expression, understood as partners' expression of feelings to each other (Cieślak, 1989; Spanier, 1976).

Statistical analysis was performed using SPSS 20 . Using the program a series of Student's $t$-tests was conducted for independent samples and correlation analysis with Pearson's $r$-coefficient.

\section{RESULTS}

Analysing the sexual activity of the subjects in the last four weeks before participating in the study, we can conclude that $68.9 \%$ of women were sexually active, while $31.1 \%$ of women did not engage in sexual activity with a partner for the past four weeks. The data show that only a quarter of women $(27.8 \%)$ were sexually active more than once a week, while $19 \%$ of them were sexually active about once every week. However, $21 \%$ of women were sexually active less frequently than a few times a month.

Analyzing the results obtained in terms of sexual dysfunction, we can conclude that the most common dysfunctions among the respondents included desire disorders (55.7\%), arousal disorders (in terms of a cognitive component) (39.3\%), as well as arousal sensation disorders (36.1\%). Dyspareunia was a rarely reported problem in the examined group (6.6\%). Approximately three quarters of women experienced no problems related to pain. In addition, $41 \%$ of women were classified in the borderline group of sexual dysfunctions on the sexual satisfaction subscale. The collective results are presented in Table 2.

Table 2 presents the percentage results obtained in the SFQ28, divided into: HPFSD - high probability of female sexual dysfunction; BSF - borderline sexual function; HPNSF - high probability of normal sexual function.

Results obtained in the SFQ28 scale are presented in Figure 1. Women with a normal course of pregnancy differ significantly from women with pregnancy complications in terms of results obtained on the scale of desire, arousal (sensations), orgasm and satisfaction. Average results obtained in both groups indicate that on the above-mentioned scales women with a normal course of pregnancy score significantly higher than those with pregnancy complications. This means that women with a normal course of pregnancy feel a stronger desire for sexual activity and desire to experience pleasure and score higher on the scale of orgasm and satisfaction with sexual activity.

Pregnancy pathology is not related to the quality of sexual life, but it correlates positively with the quality of marital relations in terms of satisfaction and emotional expression, which means that this group of 
Table 2

Percent of the average value of the likelihood of sexual dysfunction. Source: own work

\begin{tabular}{|c|c|c|c|c|c|c|c|}
\hline $\begin{array}{c}\text { Measure- } \\
\text { ment }\end{array}$ & Desire & $\begin{array}{c}\text { Arousal } \\
\text { (sensa- } \\
\text { tions) }\end{array}$ & $\begin{array}{c}\text { Arousal } \\
\text { (lubrica- } \\
\text { tion) }\end{array}$ & $\begin{array}{c}\text { Arousal } \\
\text { (cognitive } \\
\text { components) }\end{array}$ & Orgasm & Pain & $\begin{array}{l}\text { Satisfac- } \\
\text { tion with } \\
\text { sex }\end{array}$ \\
\hline HPFSD $(\%)$ & 55.7 & 36.1 & 27.9 & 39.3 & 27.9 & 6.6 & 16.4 \\
\hline BSF $(\%)$ & 32.8 & 13.1 & 32.8 & 14.8 & 26.2 & 14.8 & 41.0 \\
\hline HPNSF (\%) & 11.5 & 24.6 & 13.1 & 19.7 & 18.0 & 50.8 & 16.4 \\
\hline Total (\%) & 100.0 & 73.8 & 73.8 & 73.8 & 72.1 & 72.1 & 73.8 \\
\hline Lack (\%) & & 26.2 & 26.2 & 26.2 & 27.9 & 27.9 & 26.2 \\
\hline
\end{tabular}

Sexual activity of pregnant women women is characterized by higher satisfaction with the relationship, and greater need to be in the relationship and express feelings to each other, than in the case of the group of women with a normal course of pregnancy. The data are presented in Figure 2.

In both groups, with increasing length of pregnancy there are decreasing results on the scale of satisfaction with sexual life, arousal (sensations) and orgasm. With every subsequent week of pregnancy it turned out that the satisfaction with sexual life was decreasing, women experienced a lower level of arousal and they had difficulties in climaxing. The results are presented in Table 3.

The quality of sexual life correlates significantly with the quality of marital life on the scales of affectional expression and cohesion, which means that the higher the assessment of the quality of sexual life, the better the assessment of the marital life in terms of the aforementioned scales. The results are presented in Table 4.

Correlation analysis was performed with Pearson's $r$-coefficient, which is how the quality of sex life was assessed in terms of its relation with sexual activity and sex life. The analysis was performed for

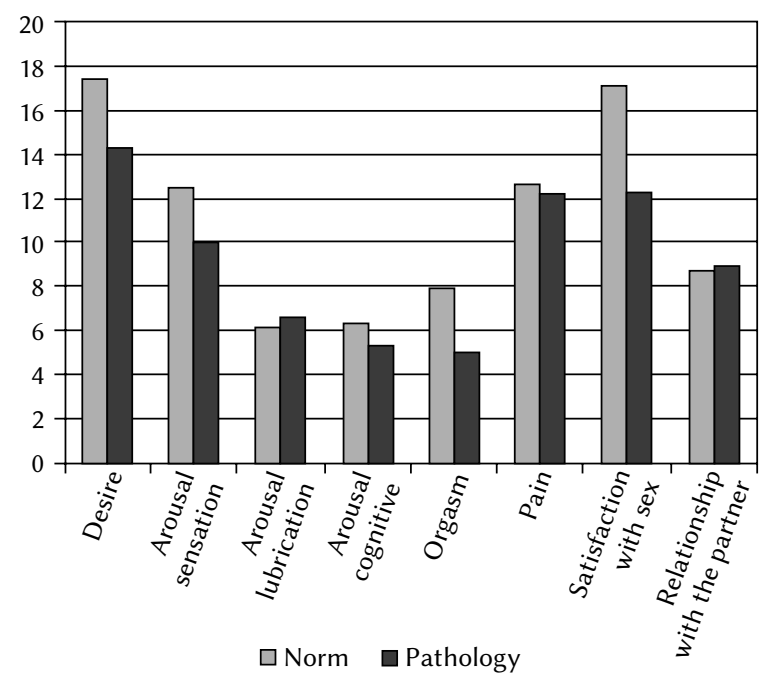

Figure 1. Average results of SFQ28 dimensions in two compared groups. Source: own work. the whole group of women. The results show that only the results of the cognitive component of arousal correlate with the quality of sex life. This means that the better the quality of sex life, the greater the arousal (but only its cognitive component). The overall result in KJS (SQoL-F) is not related to the other dimensions of the SFQ28 questionnaire. The analysis of the results included an additional verification of correlation with the division of women into two groups: with a normal course of pregnancy and with pregnancy complications. In the former group the quality of sex life correlates significantly at $p<0.05$ with the results on the scale of satisfaction with sexual intercourse and desire. It can be concluded that the high quality of sexual life also increases the results of the aforementioned two scales (satisfaction with sex, desire). In the group of pregnant women with a pathological course of pregnancy, the quality of sex life does not correlate significantly with sexual activity and life.

Table 5 presents the correlation analysis of gestational age, the quality of sexual life and the quality of marital life, conducted separately for the two groups. The relation between gestational age and the results

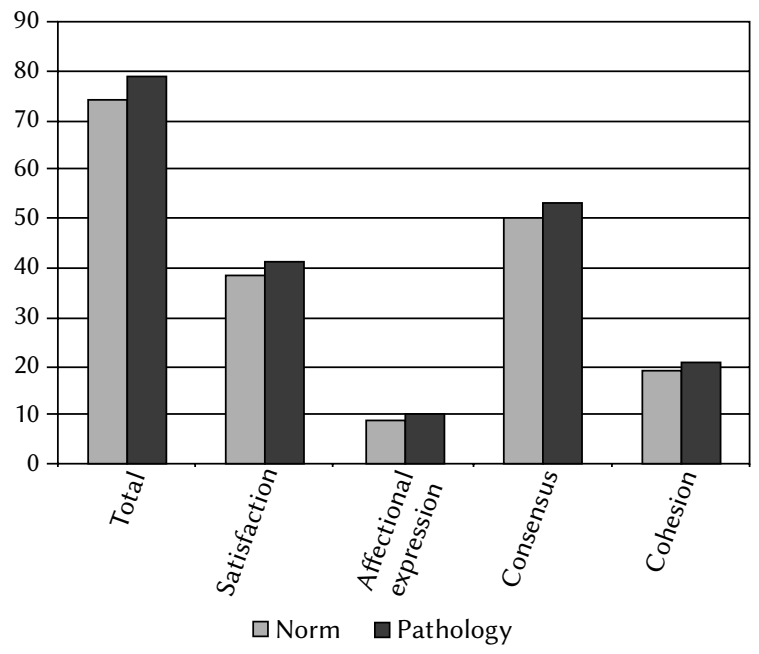

Figure 2. Average results of questionnaires SQoL-F (KJS) and DAS in two compared groups. Source: own work. 
Table 3

Analysis of correlation between the length of pregnancy and sexual activity and life. Source: own work

\begin{tabular}{ccc}
\hline & & Pregnancy week \\
\hline Desire & Pearson correlation & -0.186 \\
Arousal - sensations & Significance (bilateral) & 0.151 \\
Arousal - lubrication & Pearson correlation & -0.309 \\
Arousal - cognitive & Significance (bilateral) & 0.037 \\
components & Pearson correlation & -0.053 \\
Orgasm & Significance (bilateral) & 0.731 \\
Dyspareunia & Pearson correlation & -0.103 \\
& Significance (bilateral) & 0.502 \\
Relations in a relationship & Pearson correlation & -0.339 \\
& Significance (bilateral) & 0.008 \\
& Pearson correlation & 0.003 \\
& Significance (bilateral) & 0.985 \\
& Pearson correlation & -0.289 \\
\hline
\end{tabular}

Table 4

Analysis of correlation between the quality of sexual life and the quality of marital life. Source: own work

\begin{tabular}{ccc}
\hline & & $\begin{array}{c}\text { Sum of results } \\
\text { in the test KJS } \\
\text { (SQoL-F) }\end{array}$ \\
\hline Satisfaction & $\begin{array}{c}\text { Pearson } \\
\text { correlation } \\
\text { Significance } \\
\text { Affectional } \\
\text { expression }\end{array}$ & 0.255 \\
& $\begin{array}{c}\text { Pearson } \\
\text { correlation } \\
\text { Consensus }\end{array}$ & 0.048 \\
& $\begin{array}{c}\text { Significance } \\
\text { (bilateral) } \\
\text { Pearson } \\
\text { correlation } \\
\text { Cohesion }\end{array}$ & 0.010 \\
& $\begin{array}{c}\text { Significance } \\
\text { (bilateral) } \\
\text { Pearson } \\
\text { correlation } \\
\text { Significance } \\
\text { (bilateral) }\end{array}$ & 0.262 \\
\hline
\end{tabular}

on the scale of satisfaction in the case of women with a normal course of pregnancy proved to be significant. In this group of respondents, the higher the gestational age, the lower the results on the scale of satisfaction with their marital relation.

\section{DISCUSSION}

Our studies indicate that pregnancy changes sexual functioning.

Pregnancy causes a definite decrease in sexual activity (Lew-Starowicz \& Skrzypulec, 2010; Murtagh, 2010; Trutnovsky et al., 2006). Murtagh (2010) observed in her studies a decrease in sexual activity of pregnant women: $56 \%$ in the first trimester, $42.7 \%$ in the second trimester, and $20 \%$ in the third trimester (Murtagh, 2010). Bartellas et al. (2000) discovered that $71 \%$ of women are less sexually active during pregnancy than they used to be before (Bartellas et $a l ., 2000)$. The third trimester turns out to be the time when sexual activity is very rare. $96 \%$ of women had sexual intercourse with their partners during the first trimester, and $67 \%$ of them continued their sexual activity until the third trimester of pregnancy (Bartellas et al., 2000). Due to the limited number of women included in this study, it was not possible to analyse their sexual activity depending on the trimester. This issue was considered holistically for the entire pregnancy period. The above statements seem to be consistent with the obtained research results, in terms of sexual activity during the whole pregnancy. In this study respondents were characterized by quite a low 
Analysis of correlation between the length of pregnancy and the quality of sexual and marital life, conducted separately in two groups. Source: own work

\begin{tabular}{cccc}
\hline & & \multicolumn{2}{c}{ Pregnancy week } \\
\cline { 3 - 3 } in KJS test (SQoL-F) & & Norm & Pathology \\
\hline Satisfaction & Pearson correlation & 0.067 & 0.165 \\
& Significance (bilateral) & 0.726 & 0.375 \\
Affectional expression & Pearson correlation & -0.364 & 0.174 \\
& Significance (bilateral) & 0.048 & 0.350 \\
Consensus & Pearson correlation & -0.141 & 0.179 \\
& Significance (bilateral) & 0.457 & 0.336 \\
Cohesion & Pearson correlation & -0.353 & 0.039 \\
& Significance (bilateral) & 0.056 & 0.836 \\
& Pearson correlation & -0.065 & -0.043 \\
\hline
\end{tabular}

Sexual activity of pregnant women level of sexual activity. Despite the fact that $68.9 \%$ of women were sexually active, $31.1 \%$ of women did not engage in any sexual activity during the last four weeks of pregnancy. The obtained data indicate that about a quarter of women (27.8\%) had sexual intercourse with their partners more than once a week. In comparison, in a report on sexuality of non-pregnant Polish women (Lew-Starowicz \& Skrzypulec, 2010), $31 \%$ of women stated that they had sexual intercourse more than once a week, $52 \%$ of women stated that they did so a few times a month, but not more often than once a week (Lew-Starowicz \& Skrzypulec, 2010 ), while $16 \%$ of women stated that they had sex less frequently than a few times a month (Lew-Starowicz \& Skrzypulec, 2010). The data obtained in the present study indicate that only $19 \%$ of women engaged in sexual activity a few times a month, approximately once a week. The research results show that $21 \%$ of women were sexually active $1-2$ times in the previous month. Pregnant women were significantly less sexually active, compared to the whole Polish female population.

Sexual functioning of women with a normal course of pregnancy differs from those with pathological pregnancy. There are significant differences in sexual activity in terms of the following scales: desire, arousal (sensations), orgasm and satisfaction. Women with a normal course of pregnancy scored higher on the aforementioned scales, which means that they experience greater desire and arousal (sensations), i.e. the desire to have sex and to feel pleasure. It is worth emphasizing that the phenomenon of sexual desire has not been studied in much detail and is characterized by great individuality as far as its experiencing is concerned (Bancroft, 2011). Problems with climaxing are also individual. Some women climax very often, some rarely or never. Women with a normal course of pregnancy scored higher on the scale of orgasm and satisfaction with sexual life. Taking into consideration the whole examined group of women, 39.3\% of them reported difficulties in achieving an orgasm, with $17 \%$ of all Polish women reporting this problem, which is about $50 \%$ fewer (Lew-Starowicz \& Skrzypulec, 2010). Hormonal changes, fear of preterm delivery or the risk of miscarriage in early pregnancy, fear of harming the child during sexual intercourse, changes in the body image, difficulties in finding an appropriate sexual position and cultural disapproval of sexual intercourse during further pregnancy phases - all these factors may inhibit achieving orgasms during pregnancy (Erenel, Eroglu, Vural \& Dilbaz, 2011). The obtained results also indicate that the older the pregnant women, the greater the difficulties they have with feeling and achieving orgasm, and the lower their satisfaction with sexual activity is.

The analysis of results in terms of sexual dysfunctions revealed that pregnant women most often suffered from desire disorders (55.7\%), arousal (as a cognitive component) disorders (39.3\%) and arousal (as sensations) (36.1\%). Dyspareunia was reported rarely by the respondents $(6.6 \%)$. About three quarters of women did not experience pain problems. In addition, $41 \%$ of women belonged to the borderline group in terms of sexual dysfunctions on the satisfaction with sex scale. Bartellas et al. (2000) revealed that pain during sexual intercourse and problems with vaginal lubrication were the most frequently mentioned problems experienced by pregnant women (Bartellas et al., 2000). The obtained results are not consistent with the above statement.

Pregnancy pathology does not affect the quality of sexual life significantly, but it has a positive impact 
on the quality of a marital relation in terms of satisfaction and affectional expression. It can be concluded that women in this group are more satisfied with their relationships and have a higher need to be in a relationship than women with a normal course of pregnancy. This may be the consequence of greater support, interest and care received from the partner, when the course of pregnancy is complicated.

The results of the study conducted by Reiss, Birnbaum, Safir \& Marilyn (2012) on changes in the experience of sexuality showed a decrease in sexual pleasure with the progress of pregnancy (Reiss et al., 2012). The results of this study partially confirm the above statement. The analysis of the results leads to the conclusion that the length of pregnancy causes a decrease in performance on the scale of satisfaction with sex, arousal (sensations), and orgasm. With each week of pregnancy, it appears that satisfaction with sex decreases, and women experience lower levels of arousal and difficulty in achieving orgasm. All of these factors lead to consequential lower sexual pleasure. Murtagh (2010) reports that fatigue is the biggest predictor of decline in the frequency of sexual relations (Murtagh, 2010). In addition, low levels of desire, sexual interest and satisfaction from sex are frequent determinants of lower frequency of sexual intercourse (Murtagh, 2010).

The results of the study in relation to the entire group did not confirm the relationship between the length of pregnancy and the quality of sexual life and marriage. Research done by Reiss et al. (2012) shows that satisfaction with a relationship during pregnancy is constant, does not change (Reiss et al., 2012). However, when we compare the results divided into two groups - women with healthy and pathological pregnancies - then we will see that in women with a normal course of pregnancy, the increasing length of gestation reduces satisfaction with their marital relation.

Analysis of the results of all the women from the two groups showed that the higher the quality of sex life, the greater the arousal (cognitive component). The results showed that in the case of women with a normal course of pregnancy, the quality of sexual life determines satisfaction with sex and desire. This means that with higher subjective assessment of the quality of life in relation to sex, there is more sexual satisfaction and higher levels of desire, i.e. greater motivation, willingness and readiness for a sexual response.

Satisfaction with sexual intercourse and the sexual relationship with a partner is an important factor contributing to the quality of the marital relation. Based on the results, it can be concluded that satisfaction with sex life is related to cohesion and affectional expression in marriage. That is, the higher the quality of sexual life, the greater is the involvement of spouses in daily life issues, accompanied by a greater degree of mutual emotional expression between spouses. The observed correlation is confirmed by the literature of the subject. Ryś (1999) believes that sexual intercourse between spouses constitutes their relationship, allowing them to develop love and a marital bond. Sexual activity in a relation is a kind of marital communication. Sexual intercourse allows the needs of both partners to be satisfied, deepens the bond between spouses, and is responsible for the proper functioning of the marital relation (Ryś, 1999). Satisfactory sexual intercourse strengthens the emotional bond between partners, which in turn consolidates all other common actions (Ryś, 1999). Sydow (1999) reported that the quality of sexual life is significantly associated with satisfaction with the marital relationship. The author stresses the attractiveness of a woman. When a woman is pregnant and is perceived by herself and her partner as attractive, then it has a positive impact on sexual activity, pleasure and satisfaction with sex and affection between partners (Sydow, 1999).

Rostowski (1987) reported that satisfactory sexual intercourse strengthens the emotional bond between partners, which in turn consolidates all other common actions. The present study did not reveal any relationship between sexual activity and the quality of marital life; the obtained correlations were highly statistically insignificant. This fact may indicate that pregnancy is a specific time in which sexual activity recedes into the background and is not a factor that affects the level of satisfaction with marriage. These aspects should be considered individually, taking into account the type of problems besetting the pregnant woman, but also the sexual activity of partners before pregnancy and the quality of their relationship. It is reported in the literature of the subject that couples experiencing problems in the area of sexuality before pregnancy also have difficulties during pregnancy (Murtagh, 2010).

\section{CONCLUSIONS}

Sexuality during pregnancy is an area which has not been fully explored yet, due to the limited number of studies in this field (Murtagh, 2010). Moreover, studies often show different results of the conducted analyses (Lew-Starowicz \& Skrzypulec, 2010). Some of the research problems presented in this work are reflected in the literature of the subject and the findings of other authors. Discrepancies which occurred in some aspects require further verification and confirmation, but the reflection should also take into account individual factors affecting sexual behaviour during pregnancy. The multidimensionality of sexuality, especially during pregnancy, requires more versatile tools, and - above all - the use of qualitative methods.

Based on the conducted study, the following conclusions can be drawn:

1. Pregnant women were characterized by a relatively low level of sexual activity. 
2. Sexual functioning of women with a normal course of pregnancy differed from that of women with pregnancy complications. The former feel stronger desire and arousal (sensations), i.e. the desire for sexual activity and to experience pleasure, achieve higher scores on the orgasm scale and have greater satisfaction with sexual activity.

3. Pregnancy pathology does not significantly affect the quality of the sex life, but has a positive impact on the quality of a marital relation, in terms of satisfaction and affectional expression.

4. The higher the age of pregnant women, the greater the difficulty of feeling and achieving orgasm, and the lower the satisfaction with sexual activity.

5. The respondents reported most often desire disorders and arousal disorders (as a cognitive component and as sensations).

6. With each subsequent week of pregnancy the satisfaction with sex decreases; women feel a lower level of excitement and experience difficulties with achieving orgasms.

7. No relationship between the length of pregnancy and the quality of sexual life and marital relations was observed. In women with a normal course of pregnancy, satisfaction with their marriage decreases with growing length of gestation.

8. Satisfaction with sexual life is linked to cohesion and affectional expression in marriage.

9. No relationship between sexual activity and the quality of a marital relation was observed.

\section{RefERENCES}

Bancroft, J. (2011). Seksualność człowieka [Human Sexuality]. Wrocław: Elsevier Urban \& Partner.

Bartellas, E., Crane, J.M., Daley, M., Bennet, K.A. \& Hutchens, D. (2000). Sexuality and activity in pregnancy. BJOG, 107, 964-968.

Cieślak, K. (1989). Polska Wersja Skali G.B. Spaniera służąca do pomiaru jakości związku małżeńskiego (DAS). Przegląd Psychologiczny, 32, 1042-1049.

Erenel, A.S., Eroglu, K., Vural, G., Dilbaz, B. (2011). A Pilot Study: In What Ways Do Women in Turkey Experience a Change in Their Sexuality During Pregnancy? Sex Disabillities, 29, 207-216.

Kitzinger, S. (1983). Woman's experience of sex. London: Dorling Kindersley Limited.

Lepiarz, A. (2010). Zmiany psychiczne doświadczane przez kobiety oczekujące narodzin dziecka. Ginekologia Praktyczna, 1, 54-57.

Lew-Starowicz, M. \& Rola, R. (2012). Jakość życia seksualnego u kobiet chorujących na stwardnienie rozsiane. Przeglad Menopauzalny, 5, 381-387.

Lew-Starowicz, M. \& Lew-Starowicz, Z. (2001). Seksualność Polek. Przeglad Menopauzalny, 5, 64-75.
Lew-Starowicz, Z. (1991). Kobieta i Eros [Woman and Eros]. Warszawa: Zakład Narodowy im. Ossolińskich.

Lew-Starowicz, Z. \& Skrzypulec, V. (2010). Podstawy seksuologii [Basis of Sexology]. Warszawa: Wydawnictwo Lekarskie PZWL.

Makara-Studzińska, M.,Wdowiak, A.,Plewik, I.\& Kryś, K. (2011). Seksualność kobiet w ciąży. Seksuologia Polska, 9, 85-90.

Murtagh, J. (2010). Female sexual function, dysfunction, and pregnancy. Implications for practice. Journal of Midwifery \& Woman's Health, 55, 438-446.

Quirk, F., Haughie, S. \& Symonds, T. (2005). The use of the Sexual Functioning Questionnaire as a screening tool for women with sexual dysfunction. Journal of Sexual Medicine, 4, 469-446.

Quirk, F., Heiman, J.R., Rosen, R.C., Laan, E., Smith, M.D. \& Boolell, M.D. (2002). Development of the Sexual Function Questionnaire for Clinical Trials of Female Sexual Dysfunction. Journal of Women's Health \& Gender-based Medicine, 11, 277-289.

Reiss, S., Birnbaum, D.F., Safir, G.E. \& Marilyn, P. (2012). Changes in sexual experiences and relationship quality during pregnancy. Archives of Sexual Behavior, 41, 1241-1251.

Rosen, R.C. \& Barski, J.L. (2006). Normal sexual response in women. Obstetrics and Gynecology Clinics of North America, 33, 515-52.

Rostowski, J. (1987). Zarys psychologii matżeństwa [Basics of Marriage Psychology]. Warszawa: Państwowe Wydawnictwo Naukowe PWN.

Ryś, M. (1999). Psychologia matżeństwa w zarysie [The Psychology of Marriage: Basic Issues]. Warszawa: Centrum Metodyczne Pomocy Psychologiczno-Pedagogicznej Ministerstwa Edukacji Narodowej.

Smoliński, R. (2010). Seksualność kobiet w ciąży i połogu. In: Z. Lew-Starowicz \& V. Skrzypulec (eds.). Podstawy seksuologii [Basis of sexology]. Warszawa: Wydawnictwo Lekarskie PZWL.

Spanier, G.B. (1976). Measuring dyadic adjustment: New scales for assessing the quality of marriage and similar dyads. Journal of Marriage and the Family, 38, 15-28.

Sternberg, R.J. \& Hojjat, M. (1997). Satisfaction in close relationships. New York: Guilford Press.

Sydow, K. (1999). Sexuality during pregnancy and after childbirth: a metacontent analysis of 59 studies. Journal of Psychosomatic Research, 47, 27-49.

Symonds, T., Boolell, M., Quirk, F. (2005). Development of a questionnaire in Sexual Quality of Life in Women. Journal of Sex \& Marital Therapy, 31, 385-397.

Trutnovsky, G., Haas, J., Lang, U. \& Petru, E. (2006). Women's perception of sexuality during pregnancy and after birth. Australian and new Zealand Journal of Obstetrics and Gynaecology, 46, 282-287.
Sexual activity of pregnant women 